\title{
Thumbs Up: The effective use of music in health and wellbeing education for Australian Aboriginal youth in remote communities.
}

\begin{abstract}
The academic literature on Australian Indigenous health and wellbeing suggests an overwhelming need for education to alleviate "lifestyle” diseases and social dysfunction. Yet, the socio-cultural diversity of Australian Aboriginal communities provides a challenging landscape for efficacious and long-lasting support processes. The "Uncle Jimmy Thumbs Up!” program is facing these issues from an innovative perspective. "Thumbs up,” addresses health and wellbeing in remote Aboriginal communities from the ground up by engaging in music education programs with the youth of the community which subsequently filters through to the broader community. Based on an analysis of the effectiveness of a 'Thumbs Up' case study, this article will present preliminary recommendations for working with Australian Indigenous youth and their broader communities through facilitated musical activities. Informal learning frameworks which incorporate music-making shared between educators and community members are shown to be a constructive means of engaging youth and empowering them in the management of their health and wellbeing.
\end{abstract}

\section{Keywords}

Music, health and wellbeing, youth development, community music, Indigenous Australians. 


\section{Introduction}

The Uncle Jimmy Thumbs Up (UJTU) program works in collaboration with Australian Aboriginal elders and councils to deliver "healthy lifestyle" music education to children from remote communities, informing them of the choices required for a healthy life and encouraging healthy, active lifestyles to prevent chronic illness in future generations (Thumbs Up 2016). These programs are primarily facilitated within schools, and employ a creative environment that incorporates songwriting, music, video and new media and are underpinned by integrated community music involvement. UJTU also facilitate community store programs, 'cookups' and events, domestic violence awareness and media training so as to promote a holistic community approach to health and wellbeing in remote indigenous communities. UJTU has a long history in the delivery of these programs and is a not-forprofit charitable organisation with DGR (tax exempt) status.

In this article it is proposed that UJTU programs successfully convey positive lifestyle messaging to Australian Aboriginal children and youth through the integration of musicmaking and community engagement. This notion will be explored within contexts of youth development and community music in informal education frameworks. Particular reference will be drawn to the relevance of these concepts for Indigenous communities, and this will highlight the value of music in educational programs for Australian Aboriginal children from remote communities. A framework will be drawn from the literature concerning these topics, within which will be contextualised a case study of a 2015 collaboration between the UJTU program and an Australian tertiary institution. This initiative involved the engagement of three tertiary music students and one staff member (hereafter referred to as the university participants) working with UJTU staff during the delivery of a healthy lifestyle education program at the remote community of Mutitjulu, Uluru.

The design of the case study includes qualitative analysis of interviews with UJTU staff and university participants, which will be contextualized within the relevant literature. The focus will be on music's role in this process, and its contribution to successful student-teacher relationships and longevity of the message. To conclude this article will present recommendations for musical youth development and community practice programs aimed at educating and empowering Indigenous youth to embrace healthy lifestyles. 


\section{Indigenous Health and Wellbeing}

There has been significant research into the health and wellbeing of Indigenous Australians demonstrating, for example, links between disease and poor nutrition (Jones \& Smith, 2007); drug use and alcohol abuse (Rowley et al. 2000; Roche et al. 2013; Lopes, Flouris, \& Lindeman 2013); low levels of literacy and disengagement with formal education (Jorgensen et al. 2010; Faulkner et al. 2010); overcrowding and insufficient housing (Fien et al. 2011). There are double the instances of manifested psychological stress and suicide in Indigenous Australians as compared to other Australians (Roche et al. 2013; McCalman et al. 2016). Quality of life for Australian Aboriginal children is significantly lower than that of most Australians and alarmingly, the life expectancy and burden of disease for Aboriginal Australians has improved at a significantly slower rate as compared to Indigenous people of New Zealand and Canada (Doyle 2011).

Approaches to addressing these issues in Australian Aboriginal communities fall broadly into two categories: those which address a specific issue directly through intervention, and progressive approaches which adopt a broader community based dialogue (Flouris, Crane \& Lindeman 2016). Intervention approaches engage methodologies targeted towards particular problems and empirically evaluate the program's success or failure. These initiatives include, for example, the reduction of obesity and diabetes through healthy eating education programs (Rowley et al. 2000; Goodwin 2012); education on tobacco to reduce its consumption (Firth et al. 2012); the introduction of singing and didgeridoo playing to alleviate Asthma symptoms in young Indigenous Australians (Eley \& Norman, 2010; Eley 2013); and the implementation of a cycling program to aid in physical health and social issues (Bindon et al. 2009). While these kinds of programs have had varying degrees of success in addressing specific health-related issues, some may exacerbate existing power dynamics through their 'top down' approach, rather than empowering Indigenous Australians to manage their health and wellbeing over the long term. Favoured in this study are community-embedded approaches which incorporate collaborative learning and the creation of long-term relationships between educators and community residents. These types of programs promote an ongoing commitment by the educators to facilitate recurring program deliveries that maximizes the effectiveness of the program messaging. 
The relationships formed are intercultural. They often incorporate art, sport, dance, or music (Bartleet 2011; Fanian et al. 2015). In all of these approaches, care is taken to ensure that they are culturally relevant and embraced by the broader community itself (Morley 2015; Ngaanyatjarra Pitjantjatjara Yankunytjatjara Women’s Council \& Central Australian Youth Link up Service 2006). Within this literature, community music and youth development form the framework for this study.

\section{Community music and community development}

Higgins describes three kinds of community music: music of a specific community; the act of music making as a community; and, of particular relevance to this study, 'an intentional intervention, involving skilled music leaders, who facilitate group music-making experiences in environments that do not have set curricula' (2012: 3-4). This third format is exemplified in the research of Brydie-Leigh Bartleet, whose work in community music in Australian Aboriginal communities provides valuable insights into the power of musically-supported intercultural exchange. In 2009, Bartleet and seven music students travelled to Tennant Creek in Australia's Northern Territory, '[exchanging the] classroom for a remote Indigenous community' (2011: 20), with the goal of collaborative learning and cross-cultural discourse predicated upon the common language of music.

Bartleet's work in Tennant Creek aligns with 'Aboriginal empowerment or 'empowerment education,' an approach advocated by Komla Tsey, which explores a less intrusive means of community assistance based on empowerment and positivity rather than direct intervention, and which aims to address feelings of 'powerlessness resulting from colonisation' (Tsey \& Every 2000: 509). Tsey proposes two principles for empowering Indigenous peoples:

Firstly [...] for Aboriginal people, it is important to consider a person within their relationships so an evaluation should examine the impact of their participation on their ability to bring about changes or improvements, as defined by themselves, in their family, community and for those employed in the workplace. Secondly [...] story telling [is] an important aspect of Aboriginal culture so the evaluation should capture participants' stories of change (Tsey 2010: 8). 
The centrality of community and the founding and maintenance of strong relationships between locals and visitors is championed in the work of Chadwick and Rrurrambu, who write:

Our biggest failings with remote community delivery is the system working against itself, rather than in partnership. To overcome this, we started to look at the process of building relationships between ourselves, our remote community people, our community education centres and also the local government councils which are involved in these programs (2004: 161).

These principles of relationship building, community, and self-empowerment are key to the work of the UJTU organisation, especially with regard to youth development.

\section{Youth development}

In line with the preceding discussion of community approaches and empowerment, youth development programs are most effective when they support and encourage personal growth, connection to community and society, and responsibility, and when they empower young people towards greater self-confidence and motivation (Patterson, Gilding \& Averis 2001). Furthermore, programs which foreground fun, dynamic, and progressive content have been shown to engender greater engagement in Indigenous youth (Flouris, Crane \& Lindeman 2016), especially where there is an emphasis on education through self-empowerment, sense of place and community, and positive access to role models (Tatz 1994). This is supported by a 2006 government funded report by Ngaanyatjarra Pitjantjatjara Yankunytjatjara Women's Council \& Central Australian Youth Link up Service which provided recommendations as to how to control petrol sniffing in the remote Australian communities of Mutitjulu, Imanpa, Docker River, and Aputula. Of particular interest to this study, is the recommendation in the appendix to the report, A Good Practice Model for Youth Program Development in South Central Australia that:

A fundamental component to the success [of this program] has been the involvement of young people themselves, and the support of their families and the community. Rather than seeking to be prescriptive, these principles emphasise the necessity of developing each program in accordance with 
local needs and community conditions. The involvement of young people and their families ensures that youth program initiatives are locally driven and not externally imposed (Fietz in Ngaanyatjarra Pitjantjatjara Yankunytjatjara Women’s Council \& Central Australian Youth Link up Service 2006: 16).

Fietz specifies that to resonate with Indigenous youth, 'activities [should be] meaningful, stimulating, and culturally relevant' and founded on 'community development and participation’ (2006: 16; see also D’Abbs \& McLean 2008). Additionally, they 'should focus on the fostering of self-esteem and confidence in young people, and be based around such themes as personal development, nutrition, positive adolescent health, and the development of valued cultural skills' (Fietz in Ngaanyatjarra Pitjantjatjara Yankunytjatjara Women’s Council \& Central Australian Youth Link up Service 2006: 16).

The value of creative practices in youth development in an Indigenous context is currently under-explored, however, there are several notable recent studies. The Holyoake DRUMBEAT program utilised education in hand drumming in Australian Aboriginal youth communities to promote a sense of belonging, self-esteem, cooperation, and 'regard for their own potential,' as well as re-integrating youth into the schooling system (Faulkner et al. 2010: 104-107). Similarly, the Kotsiihtla Project, a northern Canadian art and music-based youth development program for remote Indigenous youth, utilises the creative arts as a means of empowerment. Its objectives include building self-confidence, connecting youth with role models, and developing creative and artistic skills with a focus on showing how communicating through art can aid in the resolution of problems. They describe their mission statement as:

To engage and empower youth to explore critical issues in their communities and lives and to find solutions together using creative arts (art as vehicle for social change), and to build resiliency amongst youth and promote healthy minds, bodies and spirits through the arts (Fanian et al. 2015: 3).

Through the program, participants were able to vocalize their thoughts on health and wellbeing-related challenges such alcoholism, suicide, as well as other topics. The facilitators 
expressed a desire to use art to 'stimulate conversation about challenges, strengths and changes in the community as a creative and inspiring method of knowledge translating and sharing' (Fanian et al. 2015: 7). Of particular importance to the success of these programs is that they were conducted in communities with existing relationships between the facilitators and the community, which had been cultivated over many years. Centralizing these sorts of relationships emphasises the important detail that youth development is done "with" rather than "to" the children of these communities (Flouris, Crane \& Lindeman 2016: 50-1).

Flouris, Crane and Lindeman investigated youth development programs in three Central Australian remote communities with the aim of determining factors which contributed to their success, and the extent to which communities valued such programs. Particularly relevant to this study is that youth expressed the need for 'highly localised' understandings of ‘safe and accessible spaces for expression and affirmation' (2016: 49-50); that is to say youth engagement programs need to recognize that space and place are central to understanding youth needs. Similarly, these communities valued 'context-specific programmes [sic]' within the communities surveyed, rather than 'making the mainstream organisations more Indigenous exclusive' (2016: 50). The research suggested that Indigenous Australians generally view goal-oriented programs as less engaging than programs that value the building of communities and 'incubate opportunities for more specific strategies and outcomes over time’' (Flouris, Crane \& Lindeman 2016: 51).

\section{Informal Learning in Australian Aboriginal Communities}

In his formative work on Australian Indigenous learning styles and their integration into Western schooling, Harris (1984; see also: Harris, 1980; Harris, 1982) explains that, up until recently, Aboriginal people have learnt in an entirely practical, informal, and culturallyembedded way. Their relatively recent integration into formal schooling has clashed with centuries of practice and demonstration-based methods of learning which results, in Harris' words, in 'more than a failure to communicate information; it is a failure to communicate goals and the nature of goal-oriented behaviour' (1984: 6). Moreover, Indigenous students rarely connect with notions of an intangible future - learning to get a job, to improve one's economic/cultural/social standing, and so forth - but are focused instead on their immediate situation and surroundings: how interested they are and how enjoyable and applicable they find the lesson (Harrison 2011). Formal schooling has made inroads towards merging Aboriginal cultural identity with enough 'western cultural capital' to allow Aboriginal 
students to engage actively within western society (what has been called "both-ways education”), but such endeavors are fraught with their own problems and inconsistencies (McTaggart 1991).

Regardless of the setting, whether classroom or remote community, a sensitivity to the formal versus informal divide is vital in discussions of effective Aboriginal education. Harris (1984) outlines several of the ways that the Aboriginal community of Milingimbi in the Northern Territory engaged with learning, including: through observation and imitation, through personal trial-and-error, through real-life performance, through successive approximation to the efficient end product, and through persistence and repetition, approaches that clash in fundamental ways with the decontextualized and critical modes of western teaching. Accordingly, western pedagogical ideals like "intrinsic motivation" are supplanted with qualities like curiosity and inquisitiveness (Harrison 2011: 43-44, 47). This disinterest in critical thinking and independent inquiry is partially a result of the fact that Indigenous cultural traditions often preclude critiques of incoming information: knowledge is a communal artefact passed down and so independent learning can be seen as 'manipulative and selfish' (pp. 47-48). It is certainly no coincidence then that purely abstract learning and independent inquiry, for example the classroom teaching of mathematics and science, has proven particularly unengaging for Aboriginal students over the years (Abrams, Taylor, Guo, 2013), and there is little reason to expect this condition to change fundamentally with different delivery mediums (be it math, or music).

\section{Synthesis}

The literature on community music-making, education and youth development explored here suggests that learning should be informal, fun, engaging, empowering, inclusive of the individual and of the community, and built on existing relationships. It should not be prescriptive in its approach, but rather empower Indigenous youth to recognise and develop strategies to address barriers to wellbeing, whether they be physical, mental or social. It should recognise the importance of place - 'country' in the Indigenous sense of the word and promoting dialogue rather formalised 'education'. In all cases, Indigenous learning methods should be holistic and organic, based around the necessity and practicality of everyday life within the specific contexts of their community. The key, then, is engaging the students within their own cultural (informal) learning apparatus, through practice, performance, and persistence, and with sensitivity to their community and culture. These 
practices are decolonizing in their approach; they eschew hierarchical relationships in favour of those which foster a sense of co-commitment and genuine collaboration toward a common goal.

It is proposed that the UJTU programs meet the criteria for community youth development programs in that they engage community through informal learning approaches to promote empowerment and wellbeing in Indigenous youth. They value activities that are culturally relevant, safe, and comfortable to the youths themselves, while legitimising music as an appropriate medium. They aim to empower youth towards greater faculties of communication and leadership, acknowledging the importance of health and wellbeing and building functional community dialogues where problems can be identified and overcome collaboratively. Significantly, they understand that themes of community must extend to the visitors: positive, on-going, trusting relationships are key to effective communication and education. For these reasons Indigenous community youth development programs, as described here, would seem to offer an ideal framework for the UJTU project. The following section will explore the UJTU case study presented as the basis of this article, within the context of the literature, to determine the specific ways it meets the criteria of best practice as described above.

\section{Case Study}

In 2015 the university and the Uncle Jimmy Thumbs Up! organisation drafted a memorandum of understanding that outlined an arrangement whereby one Conservatorium staff member and three students would travel to remote communities and assist the UJTU in the delivery of their healthy lifestyle music education programs for Indigenous children and youth. Consequently, in 2015 the first of these joint initiatives entailed a trip to the remote community of Mutitjulu near Uluru between the $21^{\text {st }}$ and the $27^{\text {th }}$ of June. The UJTU staff for this trip included Graham 'Buzz' Bidstrup, CEO of the Jimmy Little Foundation, and manager of the Jimmy Little Thumbs Up! program, and two JLTU team members, Joanna and Tammy. The university participants included one staff member (co-author of this article), and three students who were selected from a broad spectrum of applicants from the music program, Mikayla, Lachlan and Sophia. In November 2016, the UJTU staff and university participants took part in two separate open-ended interviews regarding the 2015 program, which will be analysed here in the context of the literature review findings, and framed by narrative of the activities engaged in during the program. 
The flight to Alice Springs soars over red sand dunes, which form snake-like lines that stretch to the horizon. The contrast of this landscape to the golden beaches and blue waters the university team had left behind was a visual metaphor for the stark cultural contrast they were about to experience. The land between Alice Springs and Uluru is flat and scarred by mining, and Uluru appears suddenly, standing strong, deep red, and enormous, for many, the heart and soul of Australia. Uluru's presence dominates the landscape, forming a constant backdrop for the interactions with the local community the university participants were about to embark on.

Yulara is the township associated with the resorts at Uluru, and these were built on the land that most of the Pitjantjatjara people of that area lived; with the arrival of the resorts, the Aboriginal community was moved to Mutitjulu on the less glamorous viewing side of Uluru. The presence of the UJTU healthy lifestyle message is evident within the Yulara community with "Thumbs Up" stickers on the healthy foods such as fruit and vegetables in the supermarket, and flyers advertising “Good Tucker” in shop windows. The UJTU logo and message can be seen throughout the community and appears to be embedded in the community's culture. This was one very prominent example of the level of community engagement which underpins the longevity of the UJTU program. It was one of the first things the student participants noticed, with one student describing how:

The "Thumbs Up” [message] is all around the town. I didn't expect to see it so much, but even in the grocery store, at the local community centre, the signs are up supporting the positive healthy mottos and things that they're trying to push out there [...] They had signs up on the shelving that said, “Uncle Jimmy Thumbs Up”. "Healthy Eating” to remind people of the image that they're spreading [...] and they're really supported in the community by all the locals as well (Mikayla 2016, pers. com. 22 November).

Another student participant described how '[...] even just interacting with the kids, you just throw the "Thumbs Up”, and everyone sort of got it. It was a bit of a universal [language], just a bit of communication between people who hadn't communicated before' (Lachlan 2016, pers. com. 22 November). Clearly, this kind of community engagement was crucial to 
the success of the program. This is supported by Graham Bidstrup, who explained that one of the primary aims of UJTU was:

[...] interconnection between us and the community. So to be able to actually get to know the people in the community is key [...] particularly, the older people in the community. It's not much point just talking to one group. You really need to talk to the whole of the community [...] that's the way aboriginal communities work as well (2016, pers. com. 25 November).

This is supported by another of the UJTU team members, Joanna, who described how 'the kids know who I am. I'm Aunty Joey now. We develop a real family bond. Especially if we continue to visit the same communities' (2016, pers. com. 25 November). She went on to describe the importance of trust in this relationship:

The whole community will like to trust the people who are going in there. And if that is the case, then the kids and the Elders are more likely to open up to you. And to contribute more to what we do out there. It's all about the Elders and the kids trusting you (2016, pers. com. 25 November).

Gaining the trust and respect of the community was a commonly occurring theme in the interviews. One team member, Tammy, described the importance of consistency in gaining that trust and respect:

When they initiate you as part of the community, it's like you have grounds there to actually make change [...] once you're one of them, or once you're respected by them, and you go to the shops and you know everybody there. You're not just a breeze-in, breeze-out face (2016, pers. com. 25 November).

She goes on to describe the negative impact of not engaging consistently with the community, saying how 'you hear the elders and you hear people in the community who say “Just more white fellas coming in and coming out. Blowing in and blowing out”' (2016, pers. com. 25 November). In support of Tammy's claims, Bartleet also emphasizes “the benefits of 
collaborating with the broader community, and the importance of careful planning to ensure such collaborations are productive (2008: 353).

The embedding of the UJTU message in the community, the clear support of this message from the community, and the impressions of the UJTU team and university participants clearly show, as was evident in the literature, that on-going and consistent community engagement and relationship building are key to the success of the program. Further to this, it became clear that it was equally important that the community had ownership of the program. As Joanna explains, '[w]e don't actually go in there with a song. We write it with the kids. They have a sense of ownership, so there's more pride there. And they want to show it off more. So then obviously, it spreads out through the community more so" (2016, pers. com. 25 November).

The importance of flexibility as to whom to engage with in the community was also raised, with Buzz describing how sometimes 'the teachers aren't on board. And then you have to find somebody else in the community. It might be the health workers, or it might be the people in the store, or it might be another way that you actually get to those kids' (2016, pers. com. 25 November). This also pointed to the wide range of people in the community that UJTU engage with. Further, not only was the UJTU message found throughout the community, but the community was also responsible for the message.

Day two of the program began with a visit by the university participants to the Uluru cultural centre, which was crucial to their understanding of the complexities of the Australian Indigenous culture, the importance of the local context, and the impact of the changes brought about by white occupation of the area. This visit prepared the students for their experience with the local teenagers at the Nyangatjatjara college, who were already working with the UJTU staff writing words of significance on the board and forming lyrics for a song when our group arrived. The words "respect”, “family”, "pride”, “choice” and "our land” supported the themes conveyed at the cultural centre. As they began working on some art work together, the relationship between the Indigenous youth and the university students was hesitant at first however, this soon changed when they started jamming on some instruments; playing music seemed to relax everyone and create a more mutual context for engagement. As the university team started jamming the song that was being written, barriers began to dissolve and a common voice emerge. Most importantly, it was fun - a word that is not often 
highlighted for educational programs in this context, but a key process of the UJTU programs that aligns with the findings from the literature above. Buzz affirmed this in saying 'I think it's how much fun you can make it, number one' (2016, pers. com. 25 November). Being fun means being informal, relaxed, and having fun yourself. As Joanna advocated, '[y]ou don't go in there being - like a hierarchy kind of thing. You go in there and you be one of the kids [...] and they relate to you more. They open up to you more' (2016, pers. com. 25 November). This was reinforced by Tammy, who described how:

You have to be really chill with them. Super chill. Don't come in with this preconception of anything that's going to happen. When you think something's going to go a certain way, and it just goes nothing like that, you just have to roll with the punches (2016, pers. com. 25 November).

Day three required the university participants to work in a makeshift recording studio in one of the hotel rooms, recording and programming a backing track of the song they had written the previous day for the local youth to sing on later in the day. A trip beforehand to the community of Mutitjulu had exposed the university participants to the harsh realities of life in remote Indigenous communities, offering a stark cultural contrast to the conditions at Yulara. As members of the UJTU team, the university participants all wore UJTU t-shirts, and as a result were greeted happily by some of the local children. The t-shirts seemed to immediately dissolve potential barriers, and all were soon engaged in playing a few instruments, an impromptu game of football, and informal chats. It was interesting to note that wherever the university team went with these T-shirts on, they received smiles from strangers, had conversations with people in the community and the children would come running to say hello. university team member Lachlan described his impression that the children were thinking that '[t]he Thumbs Up guys are coming around, it means we're going to hang, maybe play some music, hang out, talk about some positives' (2016, pers. com. 22 November). Sophia supported this in saying 'It made me feel a bit more like, you know, they already are going to accept us, in a way. Because they know that when we're coming here, it's with the most purest and generous intentions, and never anything else' (2016, pers. com. 22 November).

This is a strategic process the UJTU team promote - informal education through music, and promoting and sustaining that message through networking in the community, not only 
through focused messaging but also through music. In the case described above, music was the catalyst for the development of relationships between the university participants and the people of Mutitjulu. What is interesting to note is that whilst in community there is still a facilitation of informal education, via networking and this was an important factor in getting the healthy lifestyle message across to the broader community.

Informal education is also critical to the success of the UJTU program - both in the community and in the classroom. As university participant Mikayla noted:

They [the children] spend so much time outside. There's not that interaction with technology, or things like we have, necessarily. So the way that they learn, it's very practical. The way they get along is practical. The way they play is practical. So to then expect them to go into a classroom and want to sit there and learn words out of a dictionary, it's just - even to sit there and think about that, that connection's not maybe as smooth as people think it should be (2016, pers. com. 22 November).

Lachlan supported this, observing that ' $[\ldots]$ traditionally, they would have learned from their Elders [...] It's just very foreign to them, the whole learning experience of Westerners' (2016, pers. com. 22 November).

As Chadwick and Rrurrambu suggest, for educational programs to be successful, it is essential 'that they are happening in the people's own cultures. It's all about the community life; it's about what the community holds as being important (2004: 161). The UJTU program strongly adheres to this principle. Tammy described why she feels that Western formal education doesn't work:

What we do out here [Sydney] barely works for kids out there. It doesn't even come close to kids out there. I even find some classrooms that I go into, it's like, whoa, so much energy bouncing off the walls. People are just bouncing from floor to ceiling. It's like, we need to get out of this room, let alone pen and paper. Let's get out of this room. They seem caged and crazy....You take them outside and it's completely different. If we go outside and find a really nice spot, and let them pick a spot and just sit and 
talk for the beginning, with all this space around them, their energy is not bouncing off each other. And you can actually, for a second, just get moments in there. Whereas otherwise, you just get nothing (2016, pers. com. 25 November).

Understanding Indigenous culture and its localized nuances is key to the success of the UJTU program. Buzz describes how:

The more that we go to different areas, the more diverse you realize each part of the same culture [is]. So you know that if you're in that area, the central dessert, it's totally different to what it's like in the country up the top, far north. So the cultural significance of the place that you go to, significantly influences your process (2016, pers. com. 25 November).

This is supported by Joanna, who elaborated:

That doesn't just mean with the culture itself, but also instruments that you use and what women and men can and can't do, instrument-wise, and singing. And if you want to use language, then you do have to get permission from Elders. Or if you want to use a song line from their country, then you have to get the song man to approve it... We learn each culture of each country (2016, pers. com. 25 November).

Observing the youth at Nyangatjatjara college that afternoon, recording their singing and playing for the song they had written, it was evident that music and local culture was key to their engagement with the healthy lifestyle education. Joanna claimed that this is 'because [music] is such a massive part of our culture as well. You automatically get respect from being able to sing or being able to play an instrument. To then be able to help the kids learn that as well. Automatically, you're in with Indigenous culture' (2016, pers. com. 25 November). Mikayla described the process by which this occurred:

They were getting the kids to draw pictures that supported the message of healthy eating, the kids were drawing pictures of Indigenous people, they were drawing their flag. They were drawing their hand prints. They were 
drawing family. When we were outside, they were painting. All those things that were encouraging their background. They were using that background, that cultural [thing] that they can relate to, to help spread a message (2016, pers. com. 22 November).

After several more trips out to the Mutitjulu community and then back to the college to record and play, music and a connection to the community's culture brought everyone together, singing and talking about healthy lifestyles. Music has the 'potential to bring a community together, bring attention to an issue, offer catharsis and to overcome language and cultural barriers' (Fanian et al. 2015: 1). As Buzz noted, ‘you don’t want to preach. You want to ask them about what they do. What do you think about this? And that's why we use music. You write songs and you ask them to actually give their experiences on stuff' (2016, pers. com. 25 November). Buzz's comments clearly identify that UJTU facilitate an experience that both the children of the community and the UJTU staff engage with together. They write, record and perform music together. This approach exemplifies how youth development is being done "with" rather than "to" the kids of the community, where music is the catalyst for collaboration. Additionally, by engaging the community with ownership of the programs, the UJTU team are providing a scaffold for the entire community to engage with youth development "with" the kids. This is done through the performances in the community and the singing of the songs at school functions where many of the community elders are present.

Lachlan observed that the UJTU team:

[...] really tried to get on the same level so they understood why they were singing, not just we're singing a song because we can. I think it's [...] the way they're delivering the message through music, and they actually tend to start to look up to someone like that and have a respect and listen to someone like that (2016, pers. com. 22 November).

Joanna put forward her thoughts on the role of music describing how 'what I say to a lot of people when they do ask why we use music, is well, it is indirectly a subliminal message in music. Because it gets in without knowing. And you will actually sing the lyrics and therefore, you're learning' (2016, pers. com. 25 November). This role of music is described 
by Buzz as '[...] an engagement tool. The real work is in the connection within the community. That - and the message. The music [...] reinforces the message every time they sing that song. And they don't even know that they're doing it' (2016, pers. com. 25 November).

According to Buzz, music is an ideal tool for engagement because:

It's one of the few things that's intergenerational and inter-gender. There's not too many other things that you can do with old people, young people, boys, girls, men, women. [...] You find the style of music that they like. [...] And you find a consensus within that group of what style of music they like. So if you're playing a style of music that they like, that most people like, or can identify with, then they're more likely to sing the song. [...] It's instinctive, absolutely. And it's totally driven by what those kids get into. What they're into (2016, pers. com. 25 November).

After the recording was finished and the song mixed and edited to video, the UJTU team organized two concerts: one in the community of Mutitjulu and one on stage at the Yulara resort. On both occasions many of the youth got up on stage with the UJTU team and the university participants and performed their song live. This was an important empowering accomplishment for the youth that participated; many of them had been too shy to make eye contact, and now they were up on stage, performing to their families, their community and many of the tourists at the resort. Mikayla noted that 'playing is a big thing in Indigenous communities, and so for the kids to put themselves on display for others, that's a really big deal. [Their] enjoyment of the music does help to break down those barriers' (2016, pers. com. 22 November).

The UJTU program had placed them in an environment that promoted the great work they had done and you could see the pride many of them had from the smiles on their faces. There was an obvious sense of achievement and empowerment following the performances, and it was evident that informal education in Australian Aboriginal culture had an important role to play in fostering these attributes. As Tammy said, “I don't think you can get your educational message across without using [empowerment] as a tool. Empowering the kids, and stuff, as a tool. And I don't think you can get one without the other' (2016, pers. com. 25 November). 
Music and recognition of local culture have important roles to play in developing selfempowerment through this informal education framework, Joanna articulating this when she described how "[e]very community is a different country as well, within Australia. If they teach you things as well, about their bush tucker, or their culture within their country, then that empowers the kids and the Elders as well' (2016, pers. com. 25 November). Tammy described music as "[...] a tool, it's more for the empowering benefits that it has. You see them come out of their shell. And then they're willing to come and be more proactive in the classroom as well' (2016, pers. com. 25 November).

The informal UJTU educational process facilitates a personal bond between student and educator, and this relationship extends into the community as part of that process. However, like most types of relationships they require consistent nurturing and the UJTU team endeavour to revisit communities as often as possible. By returning and delivering regular educational programs the UJTU maintains and grows the bond between the community and the UJTU team; the community is reminded of the program and the importance of having a healthy lifestyle and the UJTU staff promotes the longevity of the message. This was a major finding of the Goodwin (2012) report for Medicines Australia that focused on the effectiveness of the UJTU programs. Goodwin suggested that to be effective "at least one workshop per year in each community is recommended” (2012: 50). Buzz highlighted the potential effectiveness of this kind of long-term engagement when referring to a program UJTU commenced in Milingimbi in 2008:

You go back now, and you can find kids that were in your class in 2008 who have now got kids, and they're now looking after their kids, and they're really healthy, and they work for families as first teachers. And it's come a complete circle. A whole circle [...] you can't get that unless you spend that time in the community (2016, pers. com. 25 November).

However, this longevity and commitment needs to be maintained between UJTU programs, and this is where strong relationships with the community are crucial. As Tammy noted, “[i]t's really important to get community people into what you're doing as well. Because you're not going to be there all the time. You need somebody, and people, and a team there that actually kind of get it. And want to keep it going' (2016, pers. com. 25 November). 
The university team left Uluru with a deepened sense of understanding not only of Australian Indigenous cultures and the challenges faced by the people in these remote communities, but also with a sense of understanding of the nuanced and diverse educational requirements needed for these communities to thrive. These are summarised in the conclusion that follows, accompanied by a list of recommendations.

\section{Conclusion}

This article has presented literature and case study data that highlights those aspects of the UJTU programs which most effectively conveyed positive lifestyle messaging for Australian Aboriginal children and youth through the integration of music-making and community engagement within an informal learning environment. Within this model it is necessary to recognise the following recommendations and music's role in the effectiveness of the UJTU programs.

- Relationships should be prioritised above specific health and wellbeing related problems. It is through these relationships that such problems can be progressively and collaboratively overcome, and this open-ended nature means that the project's relevance can endure indefinitely into the future.

- Empowering youth is often equally important to educating them. Youth with greater confidence and self-esteem are more likely to engage functionally with their community and the wider world, as well as taking greater responsibility over their own wellbeing. Writing and playing music is an empowering activity that breaks down social barriers and promotes the development of quality relationships.

- Fun is more important than results, at least initially. The program needs to have a reputation amongst the youth to maintain attendance and sustain growth over time.

- Regularity is key to the success of such a program. For this initiative to maximise effectiveness requires a commitment to ongoing connections and interactions which build trust and community engagement in ways irregular or one-off programs cannot.

- For the sake of engagement, it is imperative that the community maintain a sense of ownership over the program, believing in its outcomes and supporting its processes.

- Familiarity and security (cultural, familial, etc.) are vitally important. Program participants should be amongst people that they trust, and the program should be 
founded on local cultural customs and predicated upon a medium that they have skills in and are comfortable with.

- "In this capacity music is an ideal "mutual language” to allow "outsiders” to engage with community members and vice-versa. It is also an effective medium for the delivery of collaborative educational processes (writing songs together, for example).”

- Informal education is key to the program's success as it aligns with traditional Indigenous learning; it is the scaffolding that facilitates the delivery of the message. Music is an ideal intercultural and intergenerational vehicle for informal education.

This article has explored the efficacy of the UJTU initiative primarily through the appraisals of those involved. UJTU adheres to the principles advocated in past studies, from its employment of culturally sensitive materials, informal learning framework, prioritization of relationships and community, and dynamic and open-ended nature, to its advocacy of fun above instant results. The program's use of music underpins its observable impact in imparting positive social messages, with the overwhelmingly positive reputation of UJTU in the community evidence of its positive impact and acceptance.

The UJTU programs serve the Indigenous people by engaging youth in positive action regarding their health and wellbeing, whilst establishing an ongoing relationship with the broader community, who support the program messaging. This type of approach serves the UJTU instructors (and what they represent) by establishing the UJTU as a respected part of the community, allowing successful transition into the educational context. Community ownership and engagement is crucial to the success and longevity of the program, with the potential to perpetuate the program's aims, as the children become adults themselves, and have children of their own. In this space prevention through sustained engagement with both the children and the community, and the longevity of the message is vital to the success of the program. There is no denying the value of these programs, however, given the sociocultural diversity of many of the communities involved, it is crucial to establish a set of guidelines, determined by feedback from the communities themselves, in order to facilitate the longevity of the message. In this article, music has been presented as a scaffold that can be used to bridge some of the challenges faced by educators and community workers. Music facilitates communication between people from diverse socio-cultural backgrounds, so that they can engage with each other, and hopefully through the writing and recording of songs 
the positive messaging becomes embedded and remembered within the community. It is hoped that the fieldwork which formed the basis of this article will assist in the foundation of programs such as UJTU provide. Further investigation in this area will aid in the development of a significant and innovative opportunity that promotes positive physical, emotional and psychological wellbeing in remote Indigenous communities. 


\section{Works Cited}

Abrams, E., Taylor, P. C., \& Guo, C.-J., (2013), Contextualizing culturally relevant science and mathematics teaching for Indigenous learning. International Journal of Science and Mathematics Education, 11:1, pp. 1-21.

Bartleet, Brydie-Leigh. (2008), 'Sound links: Exploring the social, cultural and educational dynamics of musical communities in Australia', International Journal of Community Music, 1:3, pp. 335-356.

Bartleet, Brydie-Leigh. (2011), 'Stories of reconciliation: Building cross-cultural collaborations between indigenous musicians and undergraduate music students in Tennant Creek’, Australian Journal of Music Education, 2, pp. 11-21.

Bindon, J., Headly, E. J., Rissel, C., \& Wade, V., (2009), 'Improving the health and wellbeing of an urban Aboriginal men's group through a cycling promotion program', Aboriginal and Islander Health Worker Journal, 33:4, pp. 3-5.

Chadwick, G., \& Rrurrambu, G. (2004), 'Music education in remote aboriginal communities', The Asia Pacific Journal of Anthropology, 5:2, pp. 159-171. doi:10.1080/1444221042000247698

d'Abbs, P., \& MacLean, S., (2008), Volatile substance misuse: A review of interventions, Barton, Australia: Department of Health and Ageing, Commonwealth of Australia.

Doyle, Kerrie. (2011), 'Modes of colonisation and patterns of contemporary mental health: Towards an understanding of Canadian aboriginal, Australian aboriginal and Maori peoples', Aboriginal and Islander Health Worker Journal, 35:1, pp. 20-23.

Eley, R., \& Norman, M., (2010), 'Music therapy to manage asthma symptoms in young indigenous people in an urban setting', Aboriginal and Islander Health Worker Journal, 34:3, pp. 20-22. 
Eley, Robert. (2013), 'The potential effects of the didgeridoo as an indigenous intervention for Australian Aborigines: A post analysis', Music and Medicine, 5:2, pp. 84-92.

Fanian, S., Young, S. K., Mantla, M., Daniels, A., \& Chatwood, S., (2015), 'Evaluation of the Ko`, ts'iı'htła (“We Light the Fire’') Project: building resiliency and connections through strengths-based creative arts programming for Indigenous youth', International Journal of Circumpolar Health, 72.

Faulkner, S., Ivery, P., Wood, L., \& Donovan, R., (2010), 'Holyoake's Drumbeat Program: Music as a tool for social learning and improved educational outcomes' Australian Journal of Indigenous Health, 39, pp. 98-109.

Fien, J., Charlesworth, E., Lee, G., Baker, D., Grice, T., \& Morris, D., (2011), 'Life on the edge: Housing experiences in three remote Australian indigenous settlements', Habitat International, 35, pp. 343-349.

Firth, W., Crook, L., Lonesborough, A., Thompson, M., Worner, F., \& Board, W., (2012), 'Waminda's wellbeing program', Aboriginal and Islander Health Worker Journal, 36:2, pp. 20-23.

Flouris, A., Crane, P., \& Lindeman, M. A., (2016), 'Youth programmes in remote indigenous communities: Context matters', Rural Society, 25:1, pp. 37-54.

Goodwin, K. (2012). Uncle Jimmy Little Thumbs Up! Evaluation report for medicines Australia and The Jimmy Little Foundation.

Harris, S.G. (1980). Culture and Learning: Tradition and Education in North-east Arnhem Land. Darwin: Northern Territory Department of Education.

Harris, S.G. (1982). Traditional Aboriginal education strategies and their possible place in a modern bicultural school. In J.Sherwood (Ed.) Aboriginal Education: Issues and Innovations, North Perth: Western Australia Creative Research. 
Harris, S. G. (1984). Aboriginal learning styles and formal schooling, The Australian Journal of Indigenous Education, 12:4, 3-23.

Harrison, N. (2011). Teaching and Learning in Aboriginal Education, New York:

Oxford University Press.

Higgins, L. (2012), Community Music: In Theory and in Practice, New York: Oxford University Press.

Jones, R., \& Smith, F., (2007), 'Fighting disease with fruit', Australian Family Physician, 36:10, pp. 863-864.

Jorgensen, R., Grootenboer, P., Niesche, R., \& Lerman, S., (2010), 'Challenges for teacher education: the mismatch between beliefs and practice in remote Indigenous contexts', Asia-Pacific Journal of Teacher Education, 38:2, pp. 161-175.

Lopes, J., Flouris, A., \& Lindeman, M. A., (2013), 'Youth development programs in Central Australian Aboriginal communities', Youth Studies Australia, 32:1, pp. 55-62.

McCalman, J., Bainbridge, R., Russo, S., Rutherford, K., Tsey, K., Wenitong, M., Jacups, S., (2016), 'Psycho-social resilience, vulnerability and suicide prevention: impact evaluation of a mentoring approach to modify suicide risk for remote Indigenous Australian students at boarding school', BMC Public Health, 16:98.

McTaggart, R. (1991), Western institutional impediments to Australian Aboriginal education. Journal of Curriculum Studies, 23:4, pp. 297-325. doi: DOI: $10.1080 / 0022027910230401$

Morley, S. (2015), What works in effective Indigenous community-managed programs and organisations. Child Family Community Australia, 32. 
Link up Service (2006), Proposal to implement best practice youth diversionary programs in Mutitjulu, Imanpa, Docker River, Aputula and similar communities in the southern Northern Territory: Aboriginal Benefits Account Advisory Committee.

Patterson, J., Gilding, N., \& Averis, R. (2001), Good Practice in Youth Development: A Framework of Principles: Ausyouth.

Roche, A. M., Duraisingam, V., Trifonoff, A., Battams, S., Freeman, T., Tovell, A., Bates, N., (2013), 'Sharing stories: Indigenous alcohol and other drug workers' well-being, stress and burnout, Drug and Alcohol Review, 32, pp. 527-535.

Rowley, K. G., Daniel, M., Skinner, K., Skinner, M., White, G. A., \& O’Dea, K., (2000), 'Effectiveness of a community-directed 'healthy lifestyle' program in a remote Australian Aboriginal community', Australian and New Zealand Journal of Public Health, 24:2, pp. 136-144.

Tatz, C. (1994), Aborigines: Sport, Violence and Survival: A report on research project 18/1989 - ‘Aborigines: the relationship between sport and delinquency’, Criminology Research Council.

Thumbs Up. (2016), 'Good tucker long life’, http://thumbsup.org.au. Accessed 25 January 2016.

Tsey, K., \& Every, A., (2000), Evaluating Aboriginal empowerment programs: the case of Family Well-Being, Australian and New Zealand Journal of Public Health, 24:5. pp. $509-514$ 
Tsey, K. (2010). Making social science matter?: Case studies from community development and empowerment education research in rural Ghana and Aboriginal Australia. Asian Social Science, 6(1). 